\title{
Development of Eco-Friendly Soy Meal Adhesives Enhanced by Ethylene Glycol Diglycidyl Ether
}

\author{
Xingfang Yao $\mathbb{D}^{1},{ }^{1}$ Hongli Liu $\mathbb{D}^{1},{ }^{1}$ and Congcong $\mathrm{Li}^{2}$ \\ ${ }^{1}$ School of Materials Science and Engineering, Tianjin Chengjian University, 26 Jinjing Road, Tianjin 300384, China \\ ${ }^{2}$ MOE Key Laboratory of Wooden Material Science and Application, Beijing Forestry University, Beijing 100083, China \\ Correspondence should be addressed to Xingfang Yao; yaoxingfang77@126.com and Hongli Liu; lhlbh@163.com
}

Received 31 December 2018; Accepted 13 February 2019; Published 9 June 2019

Guest Editor: Changlei Xia

Copyright (c) 2019 Xingfang Yao et al. This is an open access article distributed under the Creative Commons Attribution License, which permits unrestricted use, distribution, and reproduction in any medium, provided the original work is properly cited.

\begin{abstract}
The ethylene glycol diglycidyl ether (EGDE) as a viscosity reducer, plasticizing agent, and crosslinking agent was introduced into the adhesive system to improve the properties of the soy-based adhesive. The adhesive properties including viscosity, solid content, and shear adhesion of soy protein adhesive were measured. The morphology, infrared spectra, and crystallinity of the cured adhesives were evaluated with scanning electron microscopy (SEM), Fourier transform infrared (FTIR), and X-ray diffraction (XRD). The results showed that the viscosity of soybean flour (SF) adhesive was reduced by $48 \%$ and the solid content increased from $25.9 \%$ to $31.7 \%$ with the addition of $10 \mathrm{wt} \%$ EGDE. The wet shear strength of the plywood bonded by EGDE-modified SF adhesive was significantly improved owing to the formation of crosslinking structure in the adhesive system. The SEM, FTIR, and XRD results demonstrated that the crosslinking reaction among epoxy group of EGDE, the amino group of SF, and the hydroxyl groups of polyvinyl alcohol occurred successfully during the curing process.
\end{abstract}

\section{Introduction}

Soy-based adhesives were developed in 1923 and widely used in commercial production of plywood between 1930s and 1960s, but later they were placed by petroleum-based adhesives owing to the poor adhesion property and water resistance $[1,2]$. In recent years, however, the dwindling of fossil resources and the growing concerns about the pollution of petroleum-based adhesives have been driving the development of renewable and eco-friendly materials $[3,4]$. Soybean is considered as an alternative because of its abundance, low cost, operability, renewability, and environment friendliness [5-9]. It is necessary to modify the soy-based adhesives to obtain the desired adhesion properties. Crosslinking is one major acceptable modification method [10]. The introduction of a crosslinking agent allows the soy proteins to form a threedimensional network structure, thus improving the adhesion properties of soy-based adhesives.

Soybean flour (SF) is mainly a mixture of soy proteins and carbohydrates containing many polar functional groups, such as $-\mathrm{OH},-\mathrm{NH}_{2},-\mathrm{COOH}$, and $-\mathrm{SH}[5,10]$. Thus, many chemicals can be used as a crosslinking agent for soy-based adhesives such as the chemicals with epoxy group [11, 12]. The glycerol polyglycidyl ether (GPE) is an effective crosslinking agent for bonding yellow poplar plywood, which meets the requirement for interior plywood [13]. Supporting evidence shows that glycidyl methacrylate (GMA) can successfully graft onto soy protein isolate (SPI) [14] and enzyme-treated soybean meal adhesives. Epoxy resin (EPR) can react with the amine group in soy protein and thus improve the water resistance of soy-based adhesives [10, 15]. The improved mechanical properties of soy-based bioplastic and pineapple leaf fiber 'Green' composites are attributed to the interaction between hydroxyl groups in the pineapple leaf and the epoxy groups in polyester amide grafted with glycidyl methacrylate [16].

Many efforts have been done to improve the adhesion strength and viscosity of soy-based adhesives. Polyethylene glycol (PEG) can reduce the viscosity of soy-based adhesive, which is against the shear strength owing to the lack of reactive functional groups. Polyethylene glycol diacrylate (PEGDA) was introduced as a crosslinker and viscosity reducer into the soybean adhesive system for the formation of interpenetrating networks (IPNs) in situ. The shear strength 
could not be significantly improved because of the hydrophobicity of IPNs.

The ethylene glycol diglycidyl ether (EGDE) with two epoxy groups is prepared from the reaction between ethylene glycol (EG) and epichlorohydrin (ECH) and is widely used in the chemical industry. Previous studies prove that EGDE can be used as a crosslinking agent $[17,18]$. EGDE was used as a crosslinking agent for crosslinking chitosan beads, which were then insoluble in acidic and basic media [19]. In the present study, EGDE as a viscosity reducer and crosslinker was introduced into the soy flour (SF) adhesive system. The viscosity, solid content, shear adhesion, morphology, infrared spectra, and crystallinity were evaluated to investigate the effects of EGDE on the adhesion property and water resistance of SF adhesives.

\section{Materials and Methods}

2.1. Materials. The SF with protein content of $45.2 \%$ and moisture content of 5\% was obtained from Sanhe Hopefull Group Oil Grain Food Co. Ltd. Poplar veneer with a thickness of $1.6 \mathrm{~mm}$ and moisture content of $8 \%$ was purchased from Wen'an county of Hebei province, China. Polyvinyl alcohol (PVA) was purchased from Beijing Chemical Reagents Co. The EGDE was obtained from Chuzhou Hui-Sheng Electronic Material Co., Ltd.

2.2. Preparation of SF Adhesives. The $\mathrm{SF}(25 \mathrm{~g})$ was suspended in the mixture of PVA solution ( $40 \mathrm{~g}, 5 \%)$ and tap water (35 g) at room temperature and then stirred to form a homogeneous system. Finally, the different amounts of EGDE based on weight of the adhesive were added to the above mixture and mixed uniformly.

2.3. Determination of Viscosity. The viscosity of SF adhesive was determined using a DV-II+ viscometer (Brookfield Engineering Laboratories, Middleboro, MA, USA). The viscosity was measured at room temperature and the reported values are the average of three replications.

2.4. Solid Content Measurement. The solid content was measured by using an oven-drying method. About $2 \mathrm{~g}$ (weight $\alpha$ ) of the adhesive was placed into an oven with the temperature set to $100 \pm 2^{\circ} \mathrm{C}$ for drying until a constant weight (weight $\beta$ ) was obtained. The value of the solid content was calculated with the following equation. The final solid content was the average of the value of three parallel samples.

$$
\text { Solid content }(\%)=\frac{\beta(g)}{\alpha(g)} \times 100
$$

2.5. Preparation of Plywood Samples. The adhesive was brushed uniformly onto one side of a piece of poplar veneer surface with dimensions of $400 \mathrm{~mm} \times 400 \mathrm{~mm}$ (length $\times$ width) in order to evaluate its property. The adhesive spread rate was between 180 and $200 \mathrm{~g} / \mathrm{m}^{2}$. Before being sent into the press, the three-layer plywood sample was assembled by hand. Then the assembled plywood was hot-pressed at $120^{\circ} \mathrm{C}$ and 1.0 MPa for $6 \mathrm{~min}$.
2.6. Test of Shear Strength of Plywood Samples. After being stored at ambient conditions for at least $24 \mathrm{~h}$, the three-layer plywood was cut into shear specimens with a dimension of $100 \mathrm{~mm} \times 25 \mathrm{~mm}$ for evaluation of its shear strength and water resistance. The bonded area of each specimen was $25 \mathrm{~mm} \times 25 \mathrm{~mm}$. The testing method was in accordance with the procedure described in the China National Standard Plywood-Part 3: General Specification for Plywood for General Use (GB/T 9846.3-2004). For type I plywood, the eight plywood specimens of each plywood panel were firstly soaked in boiling water for $4 \mathrm{~h}$, then dried in $63^{\circ} \mathrm{C}$ for $20 \mathrm{~h}$, and lastly reapplied in boiling water for another $4 \mathrm{~h}$. For type II plywood, the same number of specimens was soaked in $63^{\circ} \mathrm{C}$ tap water for $3 \mathrm{~h}$. For both type I and type II plywood, all of the specimens were taken out of water and cooled at room temperature for $10 \mathrm{~min}$ before testing the shear strength. The wet shear strength was measured by using a common tensile machine with a cross head speed of $10.0 \mathrm{~mm} / \mathrm{min}$. The average bonding strength was reported.

2.7. Scanning Electron Microscopy (SEM) Testing. The unmodified and modified SF adhesives samples were dried in an oven at $120 \pm 2^{\circ} \mathrm{C}$ until a constant weight was obtained. The microstructure of the adhesive was observed by a Hitachi S-3400 N (Hitachi Science System, Ibaraki, Japan) SEM. The cured adhesives were affixed to an aluminum stub with double-side adhesive tape and the surface was sputter-coated with gold before being examined under the microscope. The SEM images of the adhesives were obtained with operation conditions at an accelerating voltage of $15 \mathrm{kV}$.

2.8. Fourier Transform Infrared (FTIR) Spectroscopy. The oven was preheated to $120^{\circ} \mathrm{C}$ and then the $\mathrm{SF}$ adhesives with or without EGDE were placed in the oven to a constant weight and then ground into power. The FTIR spectra of the adhesives were recorded on a Nicolet 380 spectrometer (Nicolet Instrument Corporation, Madison, WI) over the range of 400 to $4000 \mathrm{~cm}^{-1}$ with a $4 \mathrm{~cm}^{-1}$ resolution and 32 scans.

2.9. X-Ray Diffraction (XRD). The specimens were prepared as mentioned earlier. The X-ray diffraction (XRD) spectrum investigations were recorded with a XRD diffractometer (D8, Advance, Bruker, Germany) composed of a cobalt source. The scan range was from $5^{\circ}$ to $60^{\circ}(2 \theta)$ with $2^{\circ} / \mathrm{min}$ of scanning speed at $45 \mathrm{KV}, 30 \mathrm{~mA}$.

2.10. Thermogravimetric (TG) Analysis. Thermal degradation patterns of the cured unmodified and EGDE-modified SF adhesive were studied using a TGA analysis (TGA Q50, TA instruments, USA) in a nitrogen atmosphere. The adhesives were cured at $120^{\circ} \mathrm{C}$ in a vacuum until the constant weight was obtained and ground. Then the ground powder was put into a platinum cup and scanned from the room temperature to $600^{\circ} \mathrm{C}$ at a heating rate of $10^{\circ} \mathrm{C} / \mathrm{min}$. Maximum degradation rate was calculated as mass (\%) at peak temperature divided by peak temperature. 
TABLE 1: Effects of EGDE dosage on the performance of SF adhesive and SF adhesive-based plywood.

\begin{tabular}{|c|c|c|c|c|c|c|}
\hline \multirow{2}{*}{ Sample } & \multirow{2}{*}{ EGDE dosage (wt\%) } & \multirow{2}{*}{ Viscosity $(c \mathrm{P})$} & \multirow{2}{*}{ Solid content $(\%)$} & \multirow{2}{*}{ Dry shear strength $(\mathrm{MPa})$} & \multicolumn{2}{|c|}{ Wet shear strength $(\mathrm{MPa})$} \\
\hline & & & & & $63^{\circ} \mathrm{C}^{\mathrm{b}}$ & $100^{\circ} \mathrm{C}^{\mathrm{c}}$ \\
\hline $\mathrm{A}$ & 0 & $102000 \pm 6245$ & $25.9 \pm 0.2$ & $1.24 \pm 0.12 \mathrm{CWF}^{\mathrm{a}}$ & $0.40 \pm 0.03$ & $-{ }^{\mathrm{d}}$ \\
\hline B & 2 & $99000 \pm 9539$ & $27.7 \pm 0.3$ & $1.47 \pm 0.11 \mathrm{CWF}$ & $0.76 \pm 0.05$ & $0.33 \pm 0.04$ \\
\hline $\mathrm{C}$ & 4 & $75000 \pm 4583$ & $28.9 \pm 0.3$ & $1.39 \pm 0.30 \mathrm{CWF}$ & $0.82 \pm 0.05$ & $0.42 \pm 0.02$ \\
\hline $\mathrm{D}$ & 6 & $66000 \pm 7937$ & $30.2 \pm 0.1$ & $1.62 \pm 0.10 \mathrm{CWF}$ & $0.96 \pm 0.04$ & $0.50 \pm 0.03$ \\
\hline $\mathrm{E}$ & 8 & $60000 \pm 6557$ & $30.9 \pm 0.1$ & $1.51 \pm 0.21 \mathrm{CWF}$ & $1.06 \pm 0.02$ & $0.54 \pm 0.03$ \\
\hline $\mathrm{F}$ & 10 & $53000 \pm 3606$ & $31.7 \pm 0.5$ & $1.39 \pm 0.38 \mathrm{CWF}$ & $0.81 \pm 0.01$ & $0.49 \pm 0.01$ \\
\hline
\end{tabular}

${ }^{a}$ CWF: $100 \%$ cohesive wood failure.

$\mathrm{b}$ The results from type II.

${ }^{c}$ The results from type I.

d Delamination.

\section{Results and Discussion}

3.1. Viscosity Analysis. Viscosity is one major physical property that determines the adhesive behavior. The high viscosity will lead to poor wettability and thus the adhesive cannot spread evenly on the surface of wood veneer during the hotpressed procedure. In other words, an appropriate viscosity makes the adhesives more uniform during hot pressing and increases the spread area of wood veneer and adhesives. The viscosity of EGDE-modified SF adhesive decreased with the increasing dosage of EGDE (Table 1). The viscosity was reduced slightly along with the dosage increasing from 0 to 2 wt $\%$ EGDE, but after 4 wt $\%$ EGDE, the viscosity was reduced by $26 \%$ from 102000 to $75000 \mathrm{cP}$. With the further increased dosage of EGDE, the viscosity continued to decrease. On the addition of $10 \mathrm{wt} \%$, the viscosity was reduced by $48 \%$ to $53000 \mathrm{cP}$. These results indicate that EGDE could be used as a viscosity reducer for the SF adhesive. EGDE was incorporated as a plasticizer and decreased the intermolecular interactions, molecular entanglements, and friction when SF was dissolved in water, thus reducing the viscosity.

3.2. Solid Content Analysis. The experimental results showed that the lower viscosity and the higher solid content resulted in higher wet shear strength [20]. At low solid content, a longer hot-pressed cycle was needed to remove the superfluous water from the adhesives during the hot-pressed process. The solid content continued to rise with the increased EGDE dosage in Table 1 . The solid content of the unmodified SF adhesive was only $25.9 \%$, which was not suitable for the hot-pressed process since more than $70 \%$ of water in the adhesive should be removed. After addition of $6 \mathrm{wt} \% \mathrm{EGDE}$, the solid content of the modified SF adhesive already reached $30.2 \%$.

3.3. Dry Shear Strength. The dry shear strength for both unmodified and EGDE-modified SF adhesive-based plywood specimens met the requirement of Chinese national standard (GB/T 9846.3-2004, श0.7 MPa) (Table 1). However, the wood failure was $100 \%$ for almost all of the specimens. Thus, the measured value was determined by the strength of poplar veneer, and it was unable to demonstrate the effect of EGDE on the dry shear strength of the plywood.
3.4. Water Resistance. Water resistance is an important property related to wood adhesion [2]. Table 1 shows the wet shear strength of plywood bonded by different adhesives. After the $3 \mathrm{~h}$ soaking in the $63^{\circ} \mathrm{C}$ tap water, the wet shear strength was improved significantly at first with EGDE dosage of 2-8 wt\%, but decreased with further increase of EGDE dosage. When the dosage was $2 \mathrm{wt} \%$, the wet shear strength was increased by $90 \%$ from 0.40 to $0.76 \mathrm{MPa}$, which well satisfied the national standard for type II plywood $(\geq 0.70$ $\mathrm{MPa})$. With addition of $8 \mathrm{wt} \%$ EGDE, the wet shear strength of plywood was maximized to $1.06 \mathrm{MPa}$, which indicates that the water resistance was improved by adding a certain amount of EGDE. We deduced that the hydrophilic groups in the SF adhesive system were reduced in amount or hidden with the incorporation of EGDE during the curing process.

All of the unmodified SF adhesive-based plywood specimens failed in the $28 \mathrm{~h}$ boiling-dry cycle, while the EGDEmodified SF adhesive survived the cycle and yielded wet shear strength of $0.54 \mathrm{MPa}$ with addition of $8 \mathrm{wt} \%$ EGDE (Table 1). The results indicate that EGDE improved the water resistance of the EGDE-modified SF adhesive-based plywood. However, no adhesive satisfied the Chinese national standard for type I plywood ( $\geq 0.70 \mathrm{MPa})$.

Two reasons account for the improvement of the shear strength of modified SF adhesive. First, EGDE used as a crosslinking agent was introduced into the system to form a 3D network structure and, thus, significantly increased the shear strength. However, the wet shear strength was reduced with further addition of EGDE, which resulted from the hydrophilicity of excessive EGDE. Second, EGDE also acted as a plasticizing agent in this system. In general, the water evaporation leads to the reduced flowability of SF adhesive during the hot-press process. However, the incorporation of EGDE positively affected the dispersivity and leveling of SF adhesive on the surface of the poplar veneer, and then improved the adhesion property. The reaction scheme between EGDE and SF adhesive is shown in Figure 1. Each end of the molecular chain of EGDE contained an epoxy group that reacted with the amine group of soy protein. Meanwhile, the epoxy group of EGDE reacted with the hydroxyl group of PVA. Then the macromolecular structure was formed by the crosslinking reaction, which may cause the improvement of dry and wet shear strengths. 

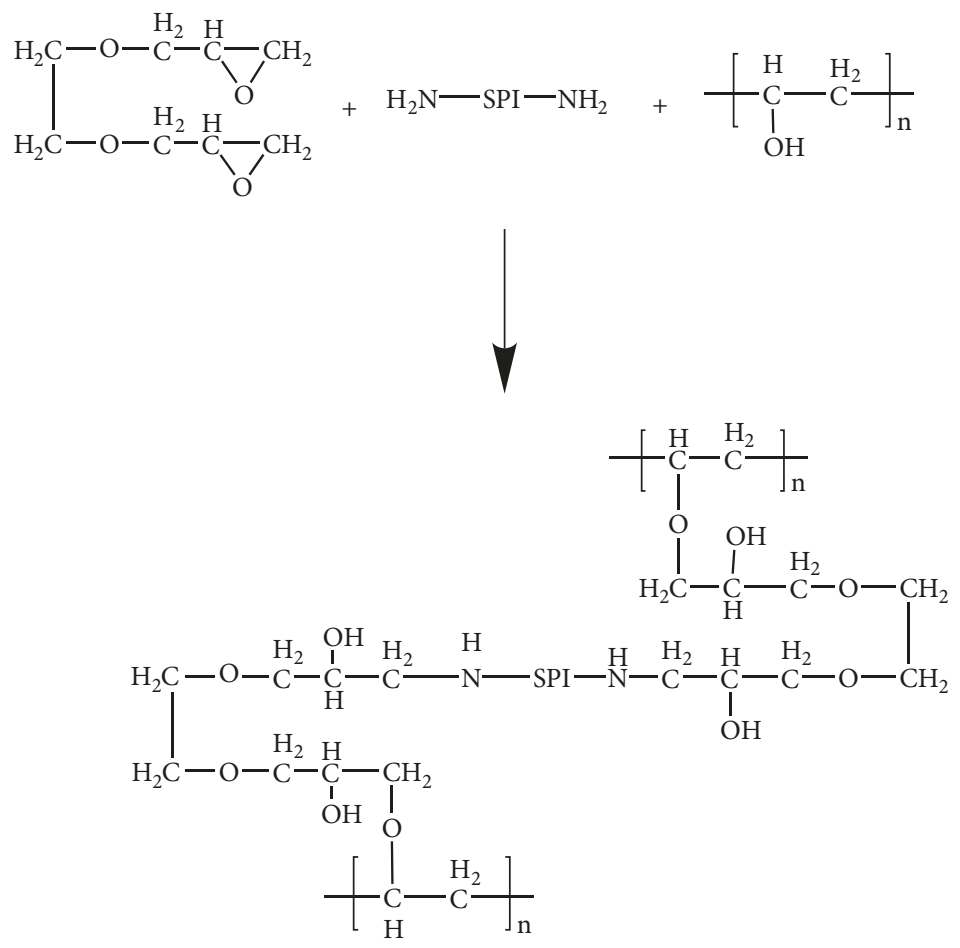

FIgURE 1: The interaction among EGDE, SF, and PVA.

3.5. SEM Analysis. The micrographs of cured adhesives are presented in Figure 2. Many holes and cracks appeared on the fractured surface of the cured unmodified SF adhesive, which were caused by the water gasification in the adhesive during the hot pressing (Figure 2(a)) (Gao et al., 2012). Therefore, the wet shear strength was poor. After the incorporation of EGDE, the micrographs showed fewer holes or cracks than the unmodified ones, indicating that EGDE alleviated the water gasification during the curing process (Figure 2(b)). With the EGDE dosage being further increased, the surface became more and more smooth (Figures 2(b)-2(f)). Table 1 clearly shows that a higher EGDE dosage leads to more crosslinking reactions with soy protein and PVA.

3.6. FTIR Spectroscopic Analysis. The FTIR spectra of cured SF adhesive and EGDE-modified SF adhesive are given in Figure 3. For SF adhesive without addition of EGDE (Figure 3(a)), the broad band within 3000 to $3500 \mathrm{~cm}^{-1}$ was assigned to the free and bound $\mathrm{N}-\mathrm{H}$ and $\mathrm{O}-\mathrm{H}$ groups. The protein characteristic absorption bands at $1655 \mathrm{~cm}^{-1}$ (amide I), $1535 \mathrm{~cm}^{-1}$ (amide II), and $1239 \mathrm{~cm}^{-1}$ (amide III) were related to $\mathrm{C}=\mathrm{O}$ stretching, $\mathrm{N}-\mathrm{H}$ bending, $\mathrm{C}-\mathrm{N}$ stretching, and $\mathrm{N}-\mathrm{H}$ bending vibration, respectively [21]. Moreover, the absorption band at $1053 \mathrm{~cm}^{-1}$ resulted from -C-NH stretching. The absorption band at $2872 \mathrm{~cm}^{-1}$ (Figures 3(b) and 3(c)) was stronger than that of SF adhesive (Figure 3(a)), which might result from the increasing content of $-\mathrm{CH}_{2}$ with the addition of EGDE. The main difference between the spectra of SF adhesives with or without EGDE lied in the absorption band at $1074 \mathrm{~cm}^{-1}$, which was assigned to $\mathrm{C}-\mathrm{O}-\mathrm{C}$ stretching resulting from aliphatic ethers after the incorporation of
EGDE. Also, the absorption band at $1404 \mathrm{~cm}^{-1}$ resulted from $\mathrm{C}-\mathrm{N}$ stretching. However, the epoxy bond was not revealed in the spectra of $6 \mathrm{wt} \%$ EGDE-modified SF adhesive, indicating that the interaction among EGDE, SF, and PVA occurred during the curing process. As the dosage of EGDE increased to $10 \mathrm{wt} \%$, no absorption band of epoxy group was observed probably because of the low EGDE content.

3.7. XRD Analysis. Figure 4 presents the XRD patterns of the unmodified and EGDE-modified SF adhesives. For the unmodified SF adhesive, there are two peaks around $2 \theta=9.5^{\circ}$ and $20.4^{\circ}$ due to the presence of PVA [22]. With the incorporation of EGDE, the peak at $2 \theta=9.5^{\circ}$ was weakened and even disappeared with the increased dosage of EGDE. The crystallinity test results of all adhesives are shown in Table 2. The crystallinity increased from $18.8 \%$ to $21.6 \%$ when the EGDE dosage was 0-6 wt\%, but slightly reduced with further addition of EGDE, because the crosslinking effect limited the rearrangement of the molecular chains. This evidence further confirmed that crosslinking interaction occurred in the adhesive system.

3.8. TGA Analysis. The TGA and differential TGA (dTG) curves of cured unmodified and EGDE-modified SF adhesives are shown in Figure 5. The weight loss of both types of adhesives degraded in three stages. In the first stage from 29 to $120^{\circ} \mathrm{C}$, about $5 \%$ weight was lost owing to the loss of residual moisture [23]. In the second stage between 190 and $400^{\circ} \mathrm{C}$, the weight loss was due to the degradation of soy proteins which involved the breakage of inter- and intramolecular hydrogen bond and electrostatic bond, and the cleavage of covalent shearing between the peptide bonds of amino acid residues. 


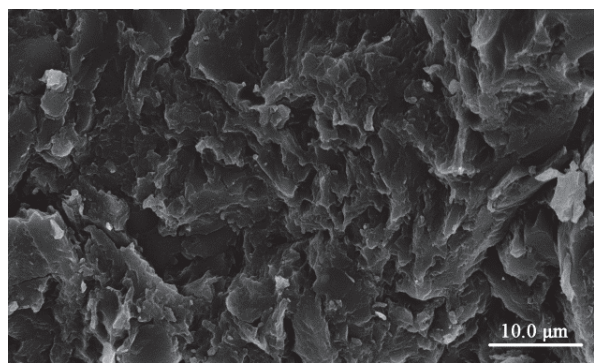

(a)

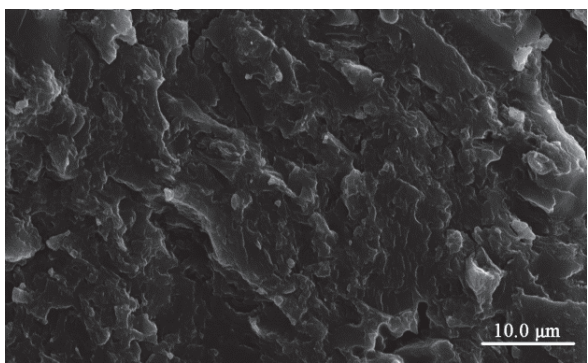

(c)

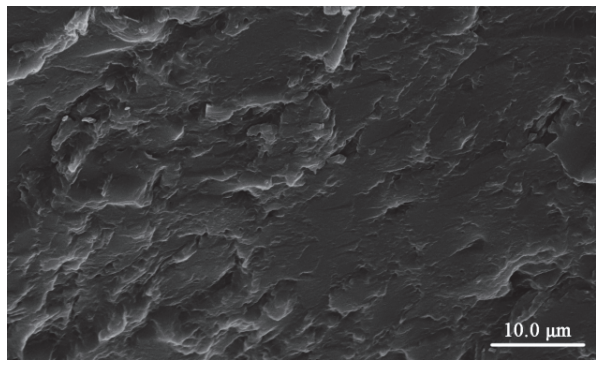

(e)

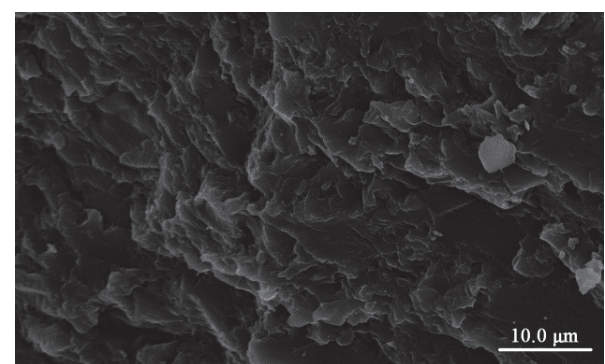

(b)

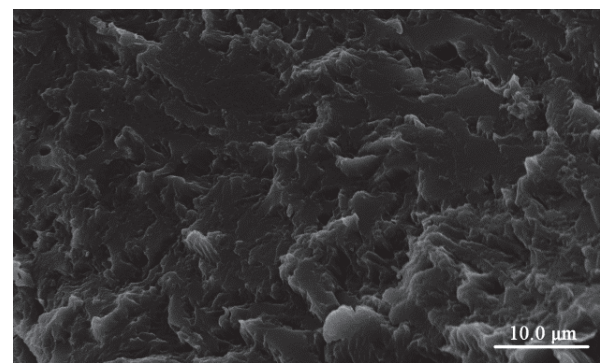

(d)

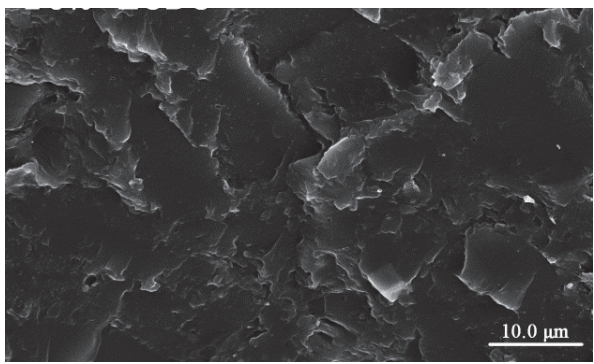

(f)

FIGURE 2: SEM micrographs of fracture surface of cured EGDE/SF adhesives.

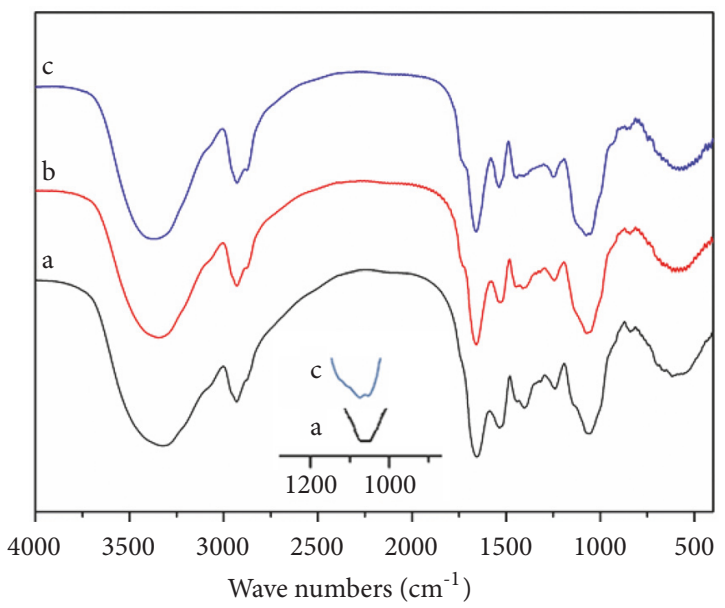

FIGURE 3: FTIR spectra of EGDE/SF adhesives: (a) A; (b) D; (c) F.

In the last stage, further heating led to the breakage of S-S, $\mathrm{O}-\mathrm{N}$, and $\mathrm{O}-\mathrm{O}$ and finally to the decomposition of protein backbone peptide bonds, thus producing various gases such as $\mathrm{CO}, \mathrm{CO}_{2}, \mathrm{NH}_{3}$, and $\mathrm{H}_{2} \mathrm{~S}[20,24]$.
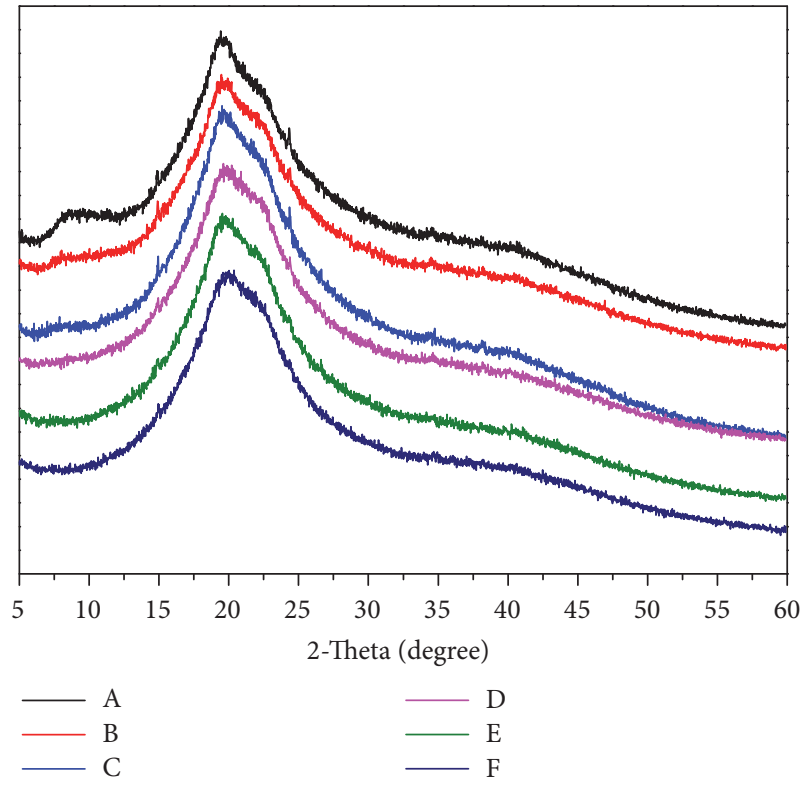

FIGURE 4: XRD diffraction patterns of unmodified and EGDEmodified SF adhesives. 


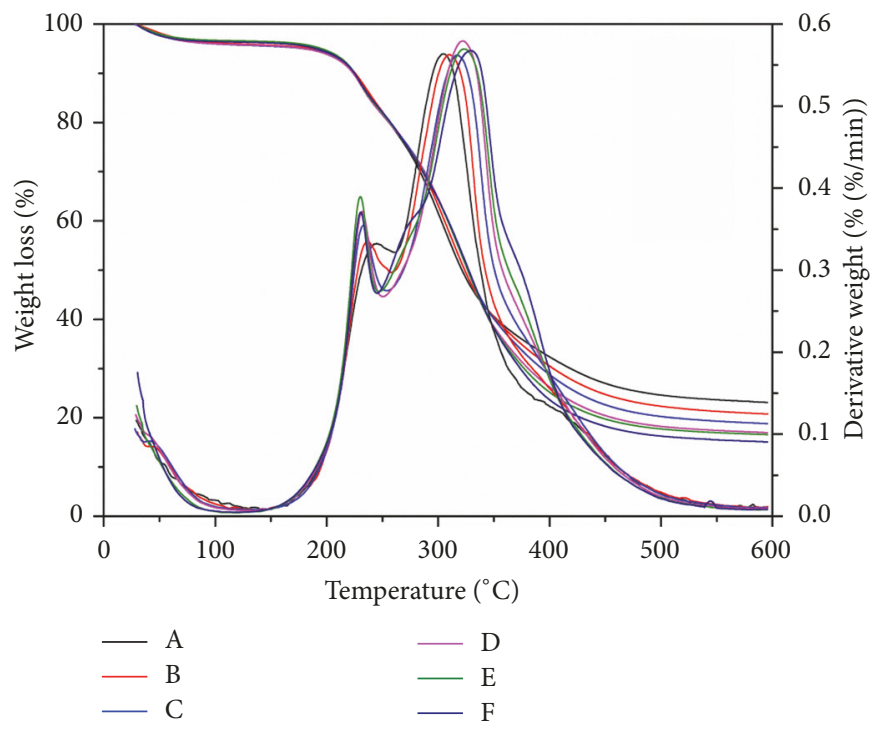

FIGURE 5: The TGA and dTG curves of cured unmodified and EGDE-modified SF adhesives.

TABLE 2: The crystallinity of unmodified and EGDE-modified SF adhesives.

\begin{tabular}{lcccccc}
\hline Sample & A & B & C & D & E & \\
\hline Crystallinity (\%) & 18.80 & 20.13 & 21.17 & 21.68 & 21.57 & 21.45 \\
\hline
\end{tabular}

TABLE 3: Thermal analysis of unmodified and EGDE-modified SF adhesives.

\begin{tabular}{|c|c|c|c|c|c|c|c|c|}
\hline \multirow{2}{*}{ Sample } & \multirow{2}{*}{$T_{i}$} & \multirow{2}{*}{$T_{m}^{a}$} & \multirow{2}{*}{$T_{m}^{b}$} & \multicolumn{4}{|c|}{$\mathrm{T}_{\mathrm{d}}$} & \multirow{2}{*}{$\mathrm{RW} \%$ at $600^{\circ} \mathrm{C}$} \\
\hline & & & & $20 \%$ & $40 \%$ & $60 \%$ & $80 \%$ & \\
\hline A & 208 & 245 & 305 & 256 & 303 & 353 & -- & 23.1 \\
\hline B & 206 & 237 & 310 & 257 & 306 & 352 & -. & 20.8 \\
\hline $\mathrm{C}$ & 205 & 233 & 317 & 256 & 309 & 350 & 511 & 18.8 \\
\hline $\mathrm{D}$ & 203 & 232 & 322 & 256 & 309 & 346 & 457 & 17.0 \\
\hline E & 201 & 230 & 323 & 257 & 309 & 346 & 446 & 16.6 \\
\hline $\mathrm{F}$ & 201 & 233 & 329 & 257 & 309 & 346 & 428 & 15.1 \\
\hline
\end{tabular}

The results of initial degradation temperature $\left(\mathrm{T}_{\mathrm{i}}\right)$, maximum pyrolysis temperature $\left(\mathrm{T}_{\mathrm{m}}\right)$, decomposition temperature with varying weight loss $\left(\mathrm{T}_{\mathrm{d}}\right)$, and residual weight (RW \%) of unmodified and modified SF adhesives are shown in Table 3. The $\mathrm{T}_{\mathrm{i}}$ and $T_{m}^{a}$ of the unmodified samples were slightly higher than in the modified ones. The main peak degradation temperature $\left(T_{m}^{b}\right)$ of modified adhesive was higher than that of the unmodified ones and $T_{m}^{b}$ increased from 305 to $329^{\circ} \mathrm{C}$ with the increasing dosage of EGDE increasing, probably because the crosslinking reaction among EGDE, SF, and PVA resulted in dense macromolecular structure and higher thermal stability. $\mathrm{T}_{\mathrm{d}}$ values were similar between the modified and the unmodified SF adhesives. $\mathrm{R}_{\mathrm{w}}$ was higher in the unmodified SF adhesive and decreased upon the addition of EGDE.

\section{Conclusions}

(1) With the incorporation of EGDE, the viscosity of SF adhesive obviously decreased and the solid content increased.

(2) The water resistance of plywood bonded by EGDEmodified SF adhesive was improved significantly compared with the unmodified SF adhesive. In addition, the water resistance of $8 \mathrm{wt} \%$ EGDE-modified $\mathrm{SF}$ adhesive was the highest, and it increased by $165 \%$ from 0.40 to $1.06 \mathrm{MPa}$, which met the Chinese national standard for type II plywood but not the type I plywood standard.

(3) SEM, FTIR, XRD, and TG suggest that the crosslinking reaction among EGDE, SF, and PVA occurred successfully during the curing process. 


\section{Data Availability}

The data used to support the findings of this study are available from the corresponding author upon request.

\section{Conflicts of Interest}

The authors declare that they have no conflicts of interest.

\section{Acknowledgments}

This work was financially supported by the Fundamental Research Funds for the Central Universities (NO. 2016ZCQ01).

\section{References}

[1] H.-N. Xu, S. Ma, W. Lv, and Z. Wang, "Soy protein adhesives improved by $\mathrm{SiO}_{2}$ nanoparticles for plywoods," Pigment \& Resin Technology, vol. 40, no. 3, pp. 191-195, 2011.

[2] S. Zhao, Z. Wang, H. Kang et al., "Fully bio-based soybean adhesive in situ cross-linked by interactive network skeleton from plant oil-anchored fiber," Industrial Crops and Products, vol. 122, pp. 366-374, 2018.

[3] N. Chen, P. Zheng, Q. Zeng, Q. Lin, and J. Rao, "Characterization and performance of soy-based adhesives cured with epoxy resin," Polymer, vol. 9, no. 10, 2017.

[4] Q. Zeng, Q. Lu, Y. Zhou, N. Chen, J. Rao, and M. Fan, "Circular development of recycled natural fibers from medium density fiberboard wastes," Journal of Cleaner Production, vol. 202, pp. 456-464, 2018.

[5] Z. Zhong, X. S. Sun, and D. Wang, "Isoelectric $\mathrm{pH}$ of polyamideepichlorohydrin modified soy protein improved water resistance and adhesion properties," Journal of Applied Polymer Science, vol. 103, no. 4, pp. 2261-2270, 2007.

[6] Y. Chen and L. Zhang, "Blend membranes prepared from cellulose and soy protein isolate in $\mathrm{NaOH} /$ thiourea aqueous solution," Journal of Applied Polymer Science, vol. 94, no. 2, pp. 748-757, 2004.

[7] G. A. Amaral-Labat, A. Pizzi, A. R. Gonçalves, A. Celzard, S. Rigolet, and G. J. M. Rocha, "Environment-friendly soy flourbased resins without formaldehyde," Journal of Applied Polymer Science, vol. 108, no. 1, pp. 624-632, 2008.

[8] Y. Zhang, Y. Li, V. K. Thakur, Z. Gao, J. Gu, and M. R. Kessler, "High-performance thermosets with tailored properties derived from methacrylated eugenol and epoxy-based vinyl ester," Polymer International, vol. 67, no. 5, pp. 544-549, 2018.

[9] Y. Zhang, V. K. Thakur, Y. Li et al., "Soybean-oil-based thermosetting resins with methacrylated vanillyl alcohol as biobased, low-viscosity comonomer," Macromolecular Materials and Engineering, vol. 303, no. 1, 2018.

[10] H. Lei, G. Du, Z. Wu, X. Xi, and Z. Dong, "Cross-linked soybased wood adhesives for plywood," International Journal of Adhesion and Adhesives, vol. 50, pp. 199-203, 2014.

[11] Y. Jang, J. Huang, and K. Li, "A new formaldehyde-free wood adhesive from renewable materials," International Journal of Adhesion and Adhesives, vol. 31, no. 7, pp. 754-759, 2011.

[12] C. May, Epoxy Resins: Chemistry And Technology, CRC Press, Boca Raton, Fla, USA, 1987.
[13] J. Huang, C. Li, and K. Li, "A new soy flour-polyepoxide adhesive system for making interior plywood," Holzforschung, vol. 66, no. 4, pp. 427-431, 2012.

[14] T. Li, N. Wang, and Q. Fang, "Incorporation of modified soy protein isolate as filier in BR/SBR blends," Journal of Materials Science, vol. 45, no. 7, pp. 1904-1911, 2010.

[15] C. Xia, L. Wang, Y. Dong et al., "Soy protein isolate-based films cross-linked by epoxidized soybean oil," RSC Advances, vol. 5, no. 101, pp. 82765-82771, 2015.

[16] W. Liu, M. Misra, P. Askeland, L. T. Drzal, and A. K. Mohanty, “'Green' composites from soy based plastic and pineapple leaf fiber: fabrication and properties evaluation," Polymer, vol. 46, no. 8, pp. 2710-2721, 2005.

[17] X. Lu, Y. Xu, C. Zheng, G. Zhang, and Z. Su, "Ethylene glycol diglycidyl ether as a protein cross-linker: A case study for crosslinking of hemoglobin," Journal of Chemical Technology and Biotechnology, vol. 81, no. 5, pp. 767-775, 2006.

[18] M. Eguchi, Y.-Z. Du, Y. Ogawa, T. Okada, N. Yumoto, and M. Kodaka, "Effects of conditions for preparing nanoparticles composed of aminoethylcarbamoyl- $\beta$-cyclodextrin and ethylene glycol diglycidyl ether on trap efficiency of a guest molecule," International Journal of Pharmaceutics, vol. 311, no. 1-2, pp. 215222, 2006.

[19] W. S. Wan Ngah, C. S. Endud, and R. Mayanar, "Removal of copper(II) ions from aqueous solution onto chitosan and crosslinked chitosan beads," Reactive \& Functional Polymers, vol. 50, no. 2, pp. 181-190, 2002.

[20] Z. Qin, Q. Gao, S. Zhang, and J. Li, "Glycidyl methacrylate grafted onto enzyme-treated soybean meal adhesive with improved wet shear strength," Bioresources, vol. 8, no. 4, pp. 5369-5379, 2013.

[21] A. Fried and D. Richter, Infrared Absorption Spectroscopy, Blackwell Publishing, Oxford, UK, 2006.

[22] K. Nakane, T. Yamashita, K. Iwakura, and F. Suzuki, "Properties and structure of poly(vinyl alcohol)/silica composites," Journal of Applied Polymer Science, vol. 74, no. 1, pp. 133-138, 1999.

[23] G. Qi and X. S. Sun, "Soy protein adhesive blends with synthetic latex on wood veneer," Journal of the American Oil Chemists' Society, vol. 88, no. 2, pp. 271-281, 2011.

[24] A. Moure, J. Sineiro, H. Domínguez, and J. C. Parajó, "Functionality of oilseed protein products: a review," Food Research International, vol. 39, no. 9, pp. 945-963, 2006. 


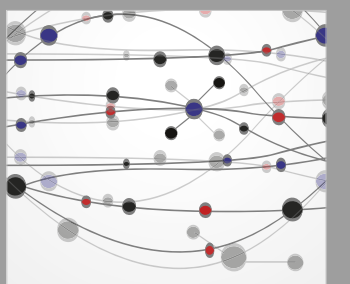

The Scientific World Journal
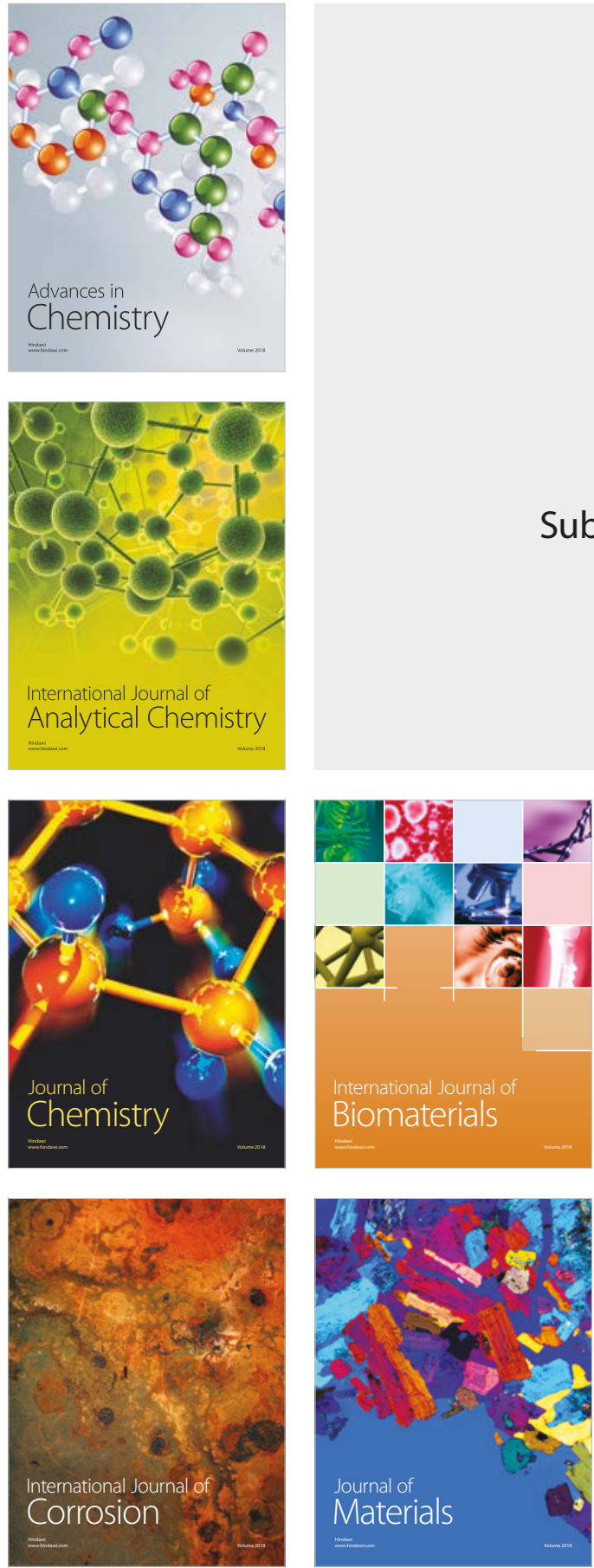

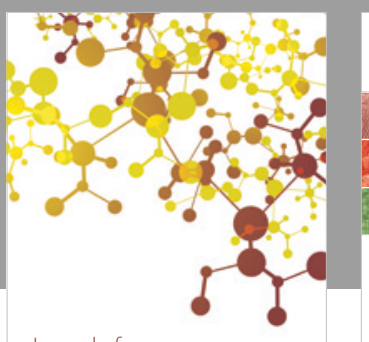

Journal of

Applied Chemistry
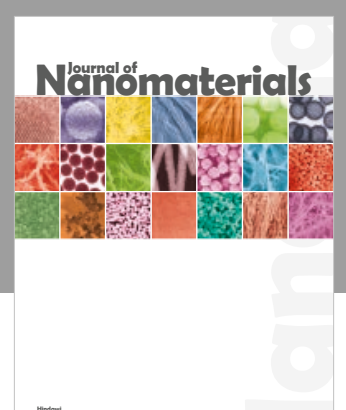

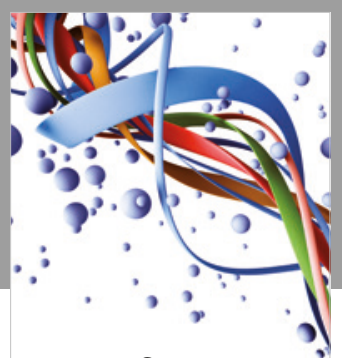

Scientifica

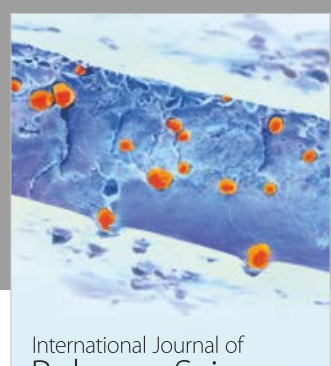

Polymer Science

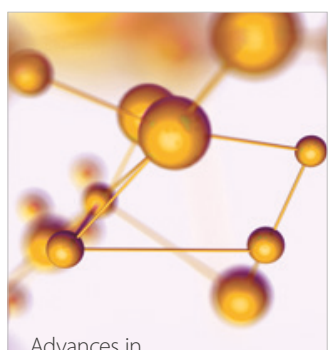

Physical Chemistry
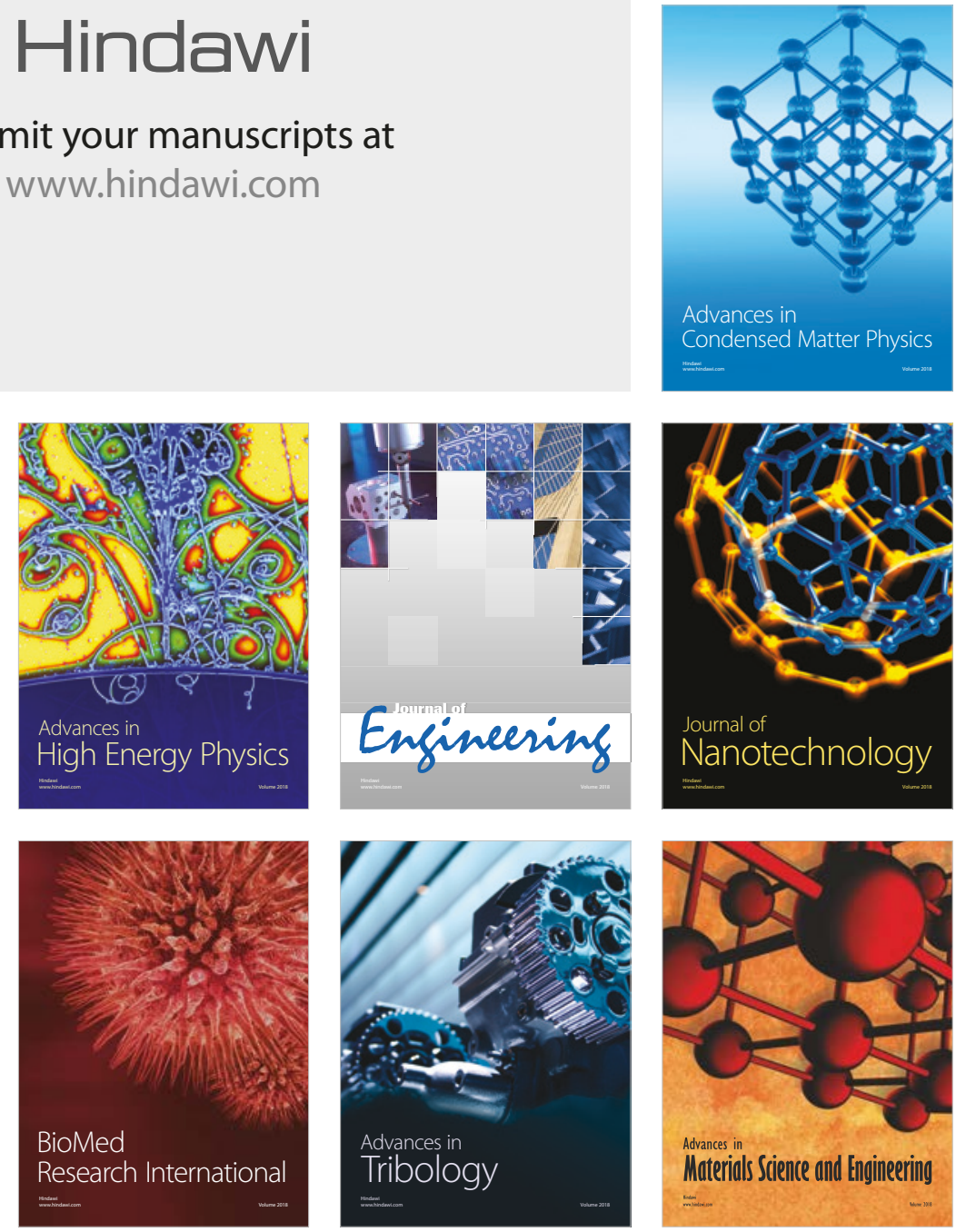